\section{Effects of Fertilizer Rate and Form on Vegetative Growth and Yield of Southern Highbush Blueberry in Pine Bark Culture}

\author{
J.G. Williamson ${ }^{1}$ and E.P. Miller
}

AdDITIONAL INDEX WORDs. Vaccinium, root system, plant nutrition

SUMMARY. Growth and yield of 'Misty' and 'Star' southern highbush blueberry (Vaccinium corymbosum hybrid) plants that were grown in pine bark culture were evaluated under several rates of granular or liquid fertilizers. Granular fertilizer resulted in larger canopy volumes and slightly greater annual fruit yield than liquid fertilizer. In 2003 and 2004, canopy growth increased linearly as fertilizer rate increased up to the highest rate tested $[81 \mathrm{~g}$ nitrogen $(\mathrm{N}), 11.8 \mathrm{~g}$ phosphorus $(\mathrm{P})$, and $44.6 \mathrm{~g}$ potassium $(\mathrm{K})$ per plant per year]. Similarly, a positive relationship was found for fruit yield and fertilizer rate during all 3 years. Berry yield was positively correlated with canopy size, and there was no relationship between fertilizer rate and berry yield per canopy volume, indicating that yield and canopy volume increased proportionally with increased fertilizer rate. Mean 'Star' berry weight was greater for granular fertilizer treatments than for liquid fertilizer treatments, but mean berry weight of 'Misty' was unaffected by fertilizer form. At the end of the experiment, visual examination of eight plants excavated by hand indicated that root systems of blueberry plants were primarily located in the pine bark layer with very few roots penetrating into the underlying soil. Limited water and nutrient holding capacities of pine bark, coupled with frequent irrigations to the shallow root systems in pine bark culture, probably resulted in considerable nutrient leaching and a high fertilizer requirement.

$\mathrm{B}$ lueberry acreage has increased rapidly in the southeastern United States during the past 5 years (U.S. Department of Agriculture, 2007). Production during the April to May market window has also increased, but prices remain strong and continued expansion of southern highbush blueberry acreage targeted for this early market is anticipated (Strik and Yarborough, 2005; U.S. Department of Agriculture, 2007; Williamson and Lyrene 2004a). Pine bark culture is currently the most common method for growing southern highbush berry (SHB) in the southeastern United States (Williamson and Lyrene, 2004b). Pine bark culture is often used where soils are not naturally suited for blueberries. In this system, pine bark beds $\approx 1.0$ to $1.3 \mathrm{~m}$ (single row) to $2.6 \mathrm{~m}$ (double row) wide by 15 to $20 \mathrm{~cm}$ deep are used as the growing medium. The physical and chemical properties of pine bark are well suited for blueberry, and plants are usually vigorous and productive provided they receive

Horticultural Sciences Department, IFAS, University of Florida, P.O. Box 110690, Gainesville, FL 32611

${ }^{1}$ Corresponding author. E-mail: jgrw@ufl.edu. adequate water and fertilizer (Clark and Moore, 1991; Heiberg and Lunde, 2006; Krewer and Ruter, 2006; Lyrene, 1990; Williamson et al., 2006). Pine bark is porous and well aerated (Davidson and Mecklenburg, 1981), and usually has a $\mathrm{pH}$ of between 4.0 and 5.0 , which is ideal for blueberry (Krewer and Ruter, 2006). Water holding capacities of pine bark vary with age and decomposition but may range from $13 \%$ to $21 \%(\mathrm{w} / \mathrm{w}$ ) (Krewer and Ruter, 2006). Pine bark also has high lignin content, and the carbon (C): $\mathrm{N}$ ratio is lower than for some other wood products such as saw dust (Krewer and Ruter, 2006). However, nutrients are subject to leaching in pine bark due to moderate cation and low anion exchange capacities (Krewer and Ruter, 2006), and in Florida, frequent irrigations are needed to prevent symptoms of water stress of mature blueberry plants grown on pine bark beds (J.G. Williamson, personal observation). Limited nutrientretaining characteristics of pine bark, combined with frequent irrigation, may have a significant effect on nutrient availability and uptake and may influence grower-adopted fertilization practices. This is particularly true if a major portion of the root system is located in the pine bark layer rather than in the underlying soil. Currently, there are no research-based fertilizer recommendations for blueberries grown in pine bark culture. This study was conducted to determine the effects of three rates of dry and liquid fertilizer on growth and yield of two SHB cultivars grown in pine bark culture in Florida.

\section{Materials and methods}

This experiment was conducted on a commercial blueberry farm in southeastern Alachua County, FL. 'Misty' and 'Star' SHB plants were planted in double-row pine bark beds on top of Lochloosa fine sand using 3 - $\mathrm{ft}$ in-row spacing with $5 \mathrm{ft}$ between rows. Each plant was allotted $\approx 15 \mathrm{ft}^{2}$ of bed space. The beds were $\approx 8$ inches deep and $10 \mathrm{ft}$ wide. Pine bark screened to 1 inch or smaller was used. Pine bark was applied to the site several months before planting in Mar. 2000. The present study was initiated in Spring 2003. Before this study, the plants were fertilized at three rates that were based on young blueberry establishment in a soil production system. Plants exhibited low vigor during 2000 and 2001, suggesting that these rates were below optimum for blueberry in pine bark culture. Fertilizer rates were increased in 2002, and again in early Spring

\begin{tabular}{llll}
\hline $\begin{array}{l}\text { Units } \\
\begin{array}{l}\text { To convert U.S. to SI, } \\
\text { multiply by }\end{array}\end{array}$ & U.S. unit & SI unit & $\begin{array}{l}\text { To convert SI to U.S., } \\
\text { multiply by }\end{array}$ \\
\hline 0.4047 & $\mathrm{acre}(\mathrm{s})$ & $\mathrm{ha}$ & 2.4711 \\
0.3048 & $\mathrm{ft}$ & $\mathrm{m}$ & 3.2808 \\
0.0929 & $\mathrm{ft}^{2}$ & $\mathrm{~m}^{2}$ & 10.7639 \\
3.7854 & gal & $\mathrm{L}$ & 0.2642 \\
2.54 & inch(es) & $\mathrm{cm}$ & 0.3937 \\
1.1209 & $\mathrm{lb} / \mathrm{acre}$ & $\mathrm{kg} \cdot \mathrm{ha}^{-1}$ & 0.8922 \\
28.3495 & $\mathrm{oz}$ & $\mathrm{g}$ & 0.0353 \\
6.8948 & $\mathrm{psi}$ & $\mathrm{kPa}$ & 0.1450
\end{tabular}


2003, at the beginning of the present study. Before the initiation of spring growth in 2003, there were no differences in estimated canopy volume among the plants that had received low, medium, or high fertilizer rates, or between plants receiving granular or liquid fertilizer during 2000 through 2002. The same plants that received low, medium, and high fertilizer rates, and liquid or granular fertilizer, during the previous years received the same designated treatments during 2003 through 2005.

The fertilizer treatments consisted of three fertilizer rates applied as granular fertilizer (every 4 weeks, eight applications per season beginning 1 March and ending 1 Oct.), or as liquid fertilizer via fertigation (every 2 weeks, 16 applications beginning 1 March and ending 15 Oct.). Fertilizer injections were made using a peristaltic pump (MasterFlex LS $^{\circledR}$; Cole-Palmer, Vernon Hills, IL). The granular fertilizer analysis was $12 \mathrm{~N}-$ 1.8P-6.6K, with $\mathrm{N}$ consisting of $3.5 \%$ nitrate, $3.5 \%$ ammonium, and $5 \%$ urea. The liquid fertilizer analysis was $24 \mathrm{~N}-3.5 \mathrm{P}-13.2 \mathrm{~K}$, with $7 \%$ nitrate, $7 \%$ ammonium, and $10 \%$ urea nitrogen. The annual fertilizer rates are given in Table 1. Because estimated plant canopy volume responded linearly to fertilizer rate during 2003 , fertilizer rates were increased in 2004 in an attempt to approach or exceed the rate needed to maximize growth in this production system. Liquid fertilizer was applied at half the amount of the dry fertilizer so that equivalent amounts of N, P, and K were applied irrespective of fertilizer form.

All plants were irrigated with Spot-Spitters ${ }^{\circledR} \quad$ (Roberts Irrigation Products, San Marcos, CA) microsprinkler emitters which covered $\approx 7.3 \mathrm{ft}^{2}$ of soil surface area and delivered $9.6 \mathrm{gal} / \mathrm{h}$ at $15 \mathrm{psi}$. Irrigated zones were centered on plants as much as possible. The irrigation system was fitted with a rain shut-off mechanism and provided $\approx 1$ inch of water per week to the irrigated area during March and April (irrigations every other day) and $\approx 1.7$ inches of water per week during June through September (daily irrigations) in the absence of rain. Where fertigation was used, fertilizer injections were near the end of the irrigation cycle.

Plant canopy volumes were estimated by measuring canopy widths in two orientations (parallel and perpendicular to the row) and plant heights. Fruit were harvested when ripe at 2 - to 3 -d intervals beginning when $\approx 5 \%$ of all fruit were ripe and continuing until all fruit were harvested. Mean berry weight was determined from 10-fruit samples collected and weighed from each plot for four consecutive harvest dates corresponding with the middle of the harvest season for each cultivar.

A two (cultivar) $\times$ two (fertilizer form $) \times$ three (fertilizer rate) factorial arrangement of treatments was used in a randomized complete block design with single-plant plots and eight replications. All plots were separated by at least one guard plant. Guard plants were fertilized by hand with granular fertilizer at the medium fertilizer rate. Because 'Misty' and 'Star' responded similarly to fertilizer rate and form during 2003 and 2004 with respect to estimated canopy volume and total berry yield, and there were no significant interactions between fertilizer rate and form, only data for 'Star' fertilized with granular fertilizer was collected during 2005.

Summer topping and modest cane-renewal pruning were done during early summer after harvest and during winter, respectively. Canopy height and width were measured after harvest and before summer pruning each year. Plots were maintained weed-free. Hand removal and postemergence herbicides were used to control weeds. Recommended practices were used to control pests and diseases (Brannen et al., 2008). At the conclusion of the study, eight 'Star' plants were carefully excavated by hand from the experimental site with their root systems intact for visual examination of the roots. Data were analyzed using the General Linear Models (GLM) procedure of SAS (version 9.1; SAS Institute, Cary, NC) for significant effects of fertilizer rates, and regression analysis was used to evaluate the curvatures of the regressions on fertilizer rates. Fertilizer types were compared using $t$ tests, and correlations for berry yield with estimated canopy volume were determined using the SAS correlation procedure.

\section{Results and discussion}

There were no significant interactions among cultivar and fertilizer rate or form for estimated canopy volume or total berry yield. Therefore, the main effects are presented for these variables.

Plant canopy volume. Canopy volume was larger for 'Star' than for 'Misty' during 2004 but not during 2003 (Table 2). 'Misty' has a relatively upright growth habit, while 'Star' tends to be more spreading (Lyrene and Ballington, 2006). Due to 'Misty's upright growth habit, summer topping during 2003 may have removed a larger percentage of the total canopy volume for 'Misty' than for 'Star', resulting in smaller plants during 2004. Mean canopy volume was slightly greater for plants

Table 1. Annual nitrogen (N), phosphorus (P), potassium (K), and fertilizer applications for 'Star' and 'Misty' southern highbush blueberry plants grown on a pine bark bed.

\begin{tabular}{|c|c|c|c|c|c|c|c|c|c|c|}
\hline \multirow[b]{4}{*}{ Rate } & & & & & & & \multicolumn{4}{|c|}{ Annual fertilizer applications (g/plant) } \\
\hline & \multicolumn{6}{|c|}{ Annual N, P, and $\mathrm{K}$ applications $\left(\mathrm{g} /\right.$ plant $^{\mathrm{z}}$} & \multirow{2}{*}{\multicolumn{2}{|c|}{$\frac{2003}{\text { Fertilizer type }^{y}}$}} & \multirow{2}{*}{\multicolumn{2}{|c|}{$\begin{array}{c}2004 \text { and } 2005 \\
\text { Fertilizer type }\end{array}$}} \\
\hline & \multicolumn{3}{|c|}{2003} & \multicolumn{3}{|c|}{2004 and 2005} & & & & \\
\hline & $\mathbf{N}$ & $\mathbf{P}$ & $\mathbf{K}$ & $\mathbf{N}$ & $\mathbf{P}$ & $\mathbf{K}$ & Granular & Liquid & Granular & Liquid \\
\hline Low & 21.0 & 3.0 & 11.5 & 48.0 & 7.0 & 26.4 & 175.0 & 87.5 & 400.0 & 200.0 \\
\hline Medium & 31.0 & 4.5 & 17.0 & 63.0 & 9.2 & 34.7 & 258.0 & 129.0 & 525.0 & 262.5 \\
\hline High & 50.0 & 7.3 & 27.5 & 81.0 & 11.8 & 44.6 & 417.0 & 208.5 & 675.0 & 337.5 \\
\hline
\end{tabular}

${ }^{\mathrm{z}} \mathrm{lg}=0.0353 \mathrm{oz}$.

${ }^{y}$ Granular $=12 \mathrm{~N}-1.8 \mathrm{P}-6.6 \mathrm{~K}$, liquid $=24 \mathrm{~N}-3.5 \mathrm{P}-13.2 \mathrm{~K}$. 
fertilized with granular than with liquid fertilizer during 2003 and 2004. This may have been due to differences in fertilizer placement between the two application methods. Most of the granular fertilizer was applied to a 2 - to 2.5 -ft-diameter circular area surrounding the plant crown. The irrigation emitter spray pattern extended beyond that area and may have extended slightly beyond the spread of the root system, depositing some of the liquid fertilizer outside of the root zone. It is also possible that liquid fertilizer, being dissolved in the soil solution, may have been more readily leached than granular fertilizer from the plant root zone. The difference in canopy volume attributed to fertilizer form was small compared with the differences observed in response to fertilizer rate. A significant positive linear relationship was found for canopy volume and fertilizer rate for 2003 and 2004. Mean canopy volumes of plants fertilized at the low rate were only about half $(2003)$ or about $75 \%$ to $80 \%$ (2004) the size of plants receiving the high fertilizer rate.

BERRY YIELD. Berry yield was greater for granular than for liquid fertilizer during 2003 and 2004 (Table 3). This difference was probably related to the greater canopy size achieved by the granular treatment. Fertilizer rate had a pronounced effect on total berry yield. A positive linear relationship between fertilizer rate and berry yield, similar to that observed for fertilizer rate and canopy volume, was observed during all 3 years. In fact, the positive response of berry yield to fertilizer rate was directly related to canopy size during 2004 and 2005. Strong correlations of estimated canopy volume with total berry yield were highly significant both years (Figs. I and 2). Furthermore, there was no relationship between fertilizer rate and berry yield per canopy volume, indicating that yield and canopy volume increased proportionally with increased fertilizer rate (data not shown).

The percentage of early or lateripening fruit was unaffected by fertilizer rate or form (data not shown). However, mean berry weight of 'Star' was greater for granular fertilizer treatments than for liquid fertilizer treatments during 2003 and 2004
(Table 4). As proposed for fertilizer form effects on canopy volume, it is possible that differences in fertilizer placement between the two fertilizer forms may have affected mean berry weight by affecting nutrient availability and uptake. This response may not have occurred in 'Misty' because the

higher fruit load of 'Misty' would result in a much lower source:sink ratio compared with 'Star' and this may have limited fruit size in 'Misty' regardless of fertilizer availability. Leaf area indices were not determined during this study, however, 'Misty' is reported to set heavy crops and foliate

Table 2. Effect of fertilizer rate and form on estimated canopy volume of 'Misty' and 'Star' southern highbush blueberry grown on a pine bark bed.

\begin{tabular}{llcc}
\hline & \multicolumn{3}{c}{ Estimated canopy vol $\left(\mathbf{m}^{3}\right)^{\mathbf{z}}$} \\
\cline { 2 - 4 } Treatment & 3 June 2003 & 7 June 2004 & 2 June 2005 $^{\mathbf{y}}$ \\
\hline Fertilizer rate & & & \\
Low & 0.602 & 1.119 & 1.292 \\
Medium & 0.745 & 1.259 & 1.472 \\
High & 1.091 & 1.474 & 1.632 \\
$P^{\text {v }}$ & $0.001(\mathrm{~L})$ & $0.001(\mathrm{~L})$ & 0.148 \\
Fertilizer type & & & - \\
Liquid & 0.754 & 1.184 & 1.465 \\
Granular & 0.871 & 1.384 & \\
$P$ & 0.038 & 0.008 & - \\
Cultivar & & & 1.465 \\
'Misty' & 0.791 & 1.183 & \\
'Star' & 0.834 & 1.386 & \\
$P$ & 0.440 & 0.006 & \\
\hline
\end{tabular}

${ }^{\mathrm{z}} 1 \mathrm{~m}^{3}=35.3147 \mathrm{ft}^{3}$

y Data for 'Star' only.

${ }^{\mathrm{x}}$ Low $=175 \mathrm{~g} /$ plant granular $(12 \mathrm{~N}-1.8 \mathrm{P}-6.6 \mathrm{~K})$ or $87.5 \mathrm{~g} /$ plant liquid $(24 \mathrm{~N}-3.5 \mathrm{P}-13.2 \mathrm{~K})$ for 2003 and $400 \mathrm{~g} /$ plant granular or $200 \mathrm{~g} /$ plant liquid for 2004 and 2005 ; medium $=258 \mathrm{~g} /$ plant granular or $129 \mathrm{~g} /$ plant liquid for 2003 and $525 \mathrm{~g} /$ plant granular or $263 \mathrm{~g} /$ plant liquid for 2004 and 2005 ; high $=417 \mathrm{~g} /$ plant granular or $208.5 \mathrm{~g} /$ plant liquid for 2003 and $675 \mathrm{~g} /$ plant granular or $338 \mathrm{~g} /$ plant liquid for 2004 and 2005; $1 \mathrm{~g}=0.0353 \mathrm{oz}$.

wData were analyzed using the General Linear Models (GLM) procedure of SAS (version 9.1; SAS Institute, Cary, NC) for significant effects of fertilizer rates, and regression analysis was used to evaluate the curvatures of the regressions on fertilizer rates $(\mathrm{L}=$ linear response to fertilizer rate at the specified level of significance). Fertilizer type was compared using $t$ tests.

Table 3. Effect of fertilizer rate and form on berry yield of 'Misty' and 'Star' southern highbush blueberry grown on a pine bark bed.

\begin{tabular}{|c|c|c|c|}
\hline \multirow[b]{2}{*}{ Treatment } & \multicolumn{3}{|c|}{ Berry yield $(\mathrm{g} / \text { plant })^{\mathrm{z}}$} \\
\hline & 2003 & 2004 & $2005^{y}$ \\
\hline \multicolumn{4}{|c|}{ Fertilizer rate ${ }^{x}$} \\
\hline Low & 581 & 2827 & 3591 \\
\hline Medium & 700 & 1060 & 4280 \\
\hline High & 1120 & 3909 & 5238 \\
\hline$P^{\mathrm{w}}$ & $0.001(\mathrm{~L})$ & $0.001(\mathrm{~L})$ & $0.007(\mathrm{~L})$ \\
\hline \multicolumn{4}{|c|}{ Fertilizer type } \\
\hline Liquid & 705 & 3089 & - \\
\hline Granular & 896 & 3528 & 4370 \\
\hline$P$ & 0.011 & 0.026 & \\
\hline \multicolumn{4}{|l|}{ Cultivar } \\
\hline 'Misty' & 998 & 3994 & - \\
\hline 'Star' & 602 & 2633 & 4370 \\
\hline$P$ & 0.001 & 0.001 & \\
\hline
\end{tabular}

${ }^{\mathrm{z}} 1 \mathrm{~g}=0.0353 \mathrm{oz}$.

2005 data for 'Star' only.

${ }^{\mathrm{x}}$ Low $=175 \mathrm{~g} /$ plant granular $(12 \mathrm{~N}-1.8 \mathrm{P}-6.6 \mathrm{~K})$ or $87.5 \mathrm{~g} /$ plant liquid $(24 \mathrm{~N}-3.5 \mathrm{P}-13.2 \mathrm{~K})$ for 2003 , and $400 \mathrm{~g} /$ plant granular or $200 \mathrm{~g} /$ plant liquid for 2004 and 2005 ; medium $=258 \mathrm{~g} /$ plant granular or $129 \mathrm{~g} /$ plant liquid for 2003 and $525 \mathrm{~g} /$ plant granular or $263 \mathrm{~g} /$ plant liquid for 2004 and 2005 ; high $=417 \mathrm{~g} /$ plant granular or $208.5 \mathrm{~g} /$ plant liquid for 2003 and $675 \mathrm{~g} /$ plant granular or $338 \mathrm{~g} /$ plant liquid for 2004 and 2005 .

wData were analyzed using the General Linear Models (GLM) procedure of SAS (version 9.1; SAS Institute, Cary, NC) for significant effects of fertilizer rates, and regression analysis was used to evaluate the curvatures of the regressions on fertilizer rates $(\mathrm{L}=$ linear response to fertilizer rate at the specified level of significance). Fertilizer type was compared using $t$ tests. 


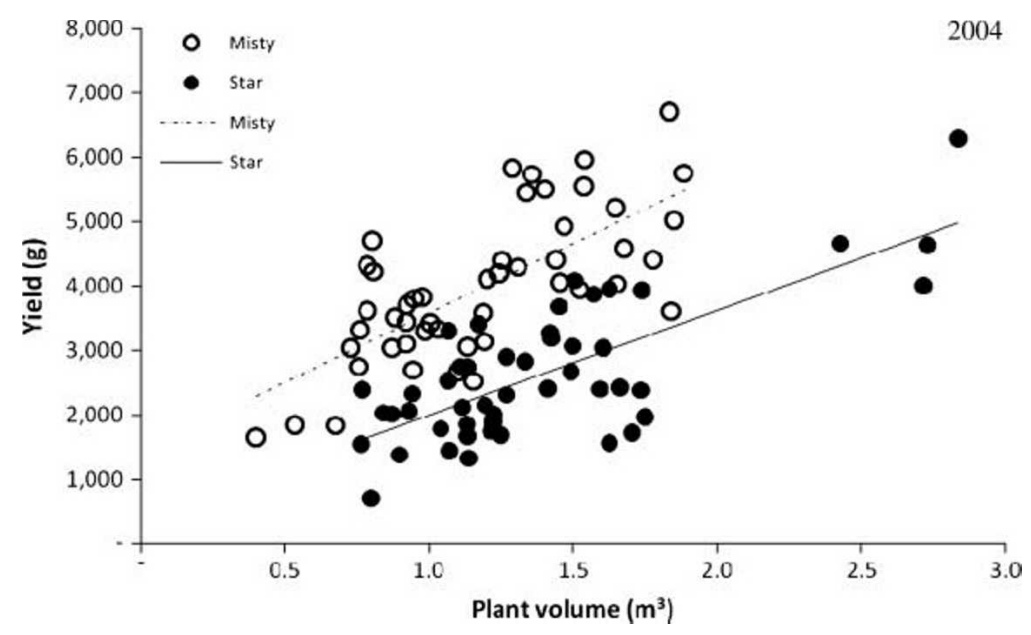

Fig. 1. The relationship between plant volume and fruit yield of 'Misty' and 'Star' southern highbush blueberry grown in pine bark culture. Correlation coefficient $(r)=0.747$ and 0.739 for 'Misty' and 'Star', respectively. Correlations for berry yield with estimated canopy volume were determined using the correlation procedure of SAS (version 9.1; SAS Institute, Cary, NC); $1 \mathrm{~m}^{3}=35.3147 \mathrm{ft}^{3}, 1 \mathrm{~g}=0.0353 \mathrm{oz}$.

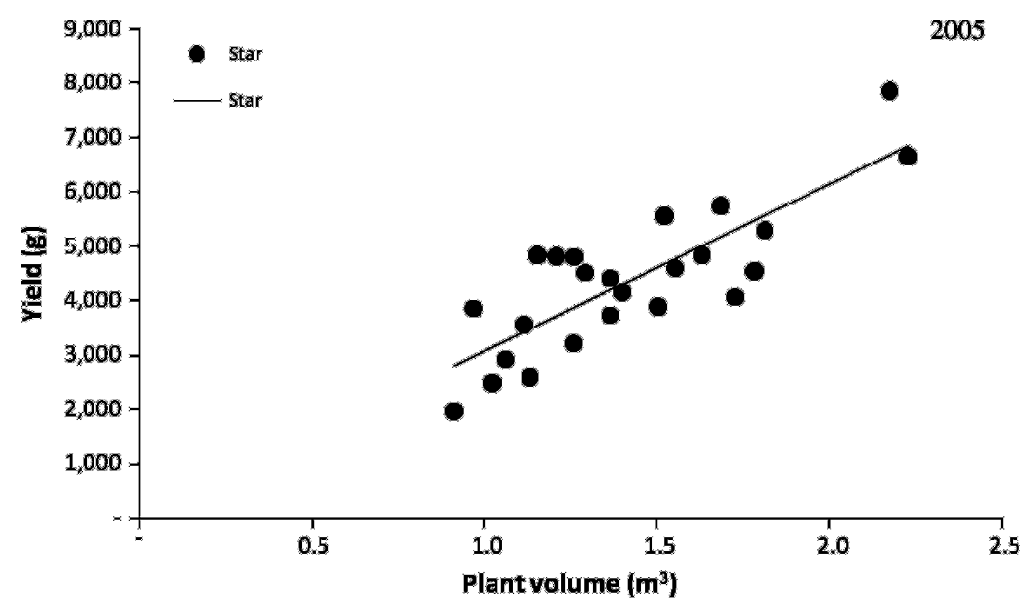

Fig. 2. The relationship between plant volume and fruit yield of 'Star' southern highbush blueberry grown in pine bark culture. Correlation coefficient $(r)=\mathbf{0 . 8 1 0}$. Correlations for berry yield with estimated canopy volume were determined using the correlation procedure of SAS (version 9.1; SAS Institute, Cary, NC); $1 \mathrm{~m}^{3}=35.3147 \mathrm{ft}^{3}, 1 \mathrm{~g}=0.0353 \mathrm{oz}$.

poorly in Florida (Williamson and Lyrene, 2004c).

Overall, fertilizer form had little effect on berry yield or canopy size. Consequently, the increased frequency of fertilizer application (every 2 weeks for liquid vs. every 4 weeks for granular) had little beneficial effect on plant growth or yield. Berry yields increased as fertilizer rates were increased up to the highest fertilizer rate tested during all 3 years. The increased berry yields can be attributed to larger canopy volumes of the plants receiving the higher rates of fertilizer because canopy size and fruit yield were positively correlated and no differences in berry yield were found among fertilizer treatments when yields were adjusted for canopy size.

Our results are similar to findings where $\mathrm{SHB}$ were grown in containers using pine bark as the growing medium (Wilber and Williamson, 2008). In that study, a positive effect on berry yield and canopy growth for 'Star' (but not 'Misty') SHB was observed for rates as high as $30 \mathrm{~g} \mathrm{~N}$ per plant per year, which was similar to the medium rate ( $31 \mathrm{~g} \mathrm{~N}$ per plant) during 2003 of the present study. In that study, canopy size and fruit yield of the container-grown plants were
Table 4. Interaction of fertilizer type and mean berry weight of 'Misty' and 'Star' southern highbush blueberry grown on a pine bark bed.

\begin{tabular}{|c|c|c|c|c|}
\hline \multirow{3}{*}{$\begin{array}{l}\text { Fertilizer } \\
\text { type }\end{array}$} & \multicolumn{4}{|c|}{ Mean berry wt $(g)^{z}$} \\
\hline & \multicolumn{2}{|c|}{2003} & \multicolumn{2}{|c|}{2004} \\
\hline & 'Misty' & 'Star' & 'Misty' & 'Star' \\
\hline Liquid & 2.0 & 2.0 & 1.6 & 2.0 \\
\hline Granular & 1.9 & 2.2 & 1.5 & 2.1 \\
\hline$P$ & 0.196 & 0.002 & 0.108 & 0.028 \\
\hline
\end{tabular}

similar to those reported here during 2003 for field-grown plants. However, fertilizer rates above $30 \mathrm{~g} \mathrm{~N}$ per plant were not tested by Wilber and Williamson (2008). In the present study, the high fertilizer rate during 2004 and 2005 applied to larger plants carrying a commercial crop was equivalent to $\approx 365 \mathrm{~kg} \cdot \mathrm{ha}^{-1} \mathrm{~N}$ per year based on 4500 plants/ha. This is a significantly higher fertilizer rate than is suggested for traditional soil culture in the southeastern United States, which is generally in the 110 to $140 \mathrm{~kg} \cdot \mathrm{ha}^{-1} \mathrm{~N}$ per year range (Krewer and Nesmith, 2006; Williamson et al., 2006).

Although root distribution was not quantified, excavation of eight 'Star' plants and examination of their root systems revealed that the vast majority of roots were located in the pine bark layer, with very few roots penetrating into the underlying soil (Figs. 3 and 4). In many cases, the pine bark layer could be pulled back by hand, revealing the interface between the bark bed and the underlying soil with very few if any roots located in the soil profile (Fig. 3 ).

Pine bark is an excellent medium for blueberry and is commonly used in containerized blueberry nurseries and containerized blueberry production systems (Whiddon, 2008). However, blueberries grown in pine bark beds on top of the soil appear to be inefficient in terms of water and fertilizer use. Newly applied pine bark will adsorb ammonium $\mathrm{N}$, making it unavailable for plant uptake. However, this equilibrium period requires only $20 \mathrm{~d}$ (Foster et al., 1983) to a few months (Krewer and Ruter, 2006) under conditions of adequate ammonium $\mathrm{N}$ application. Therefore, 


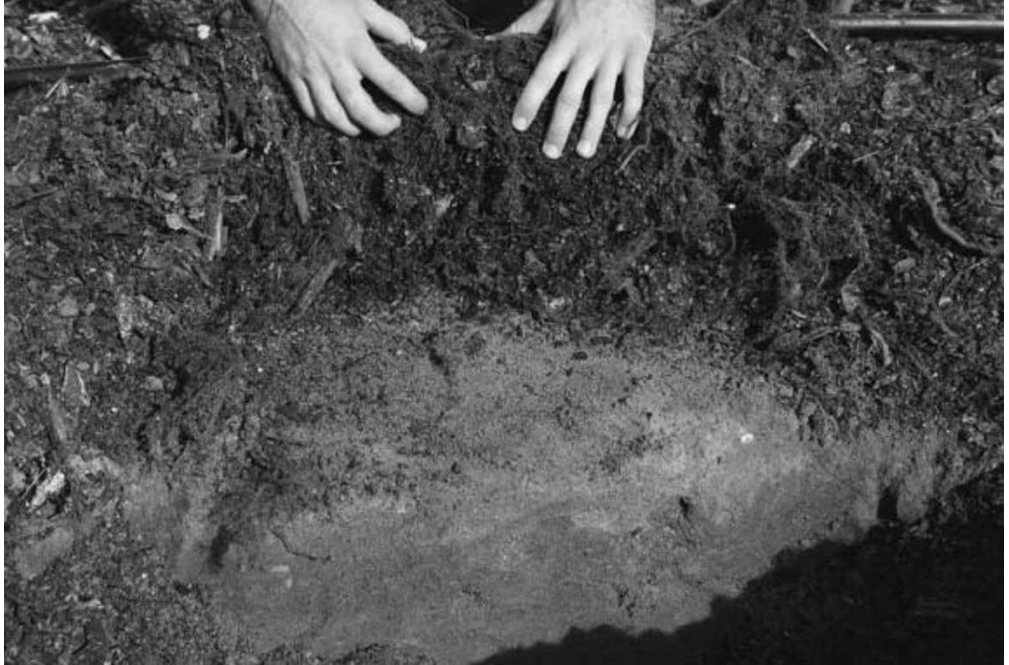

Fig. 3. Pine bark bed pulled back to reveal the underlying soil. The vast majority of the root system is confined to the pine bark layer, which is about $15 \mathrm{~cm}$ (5.9 inches) deep.

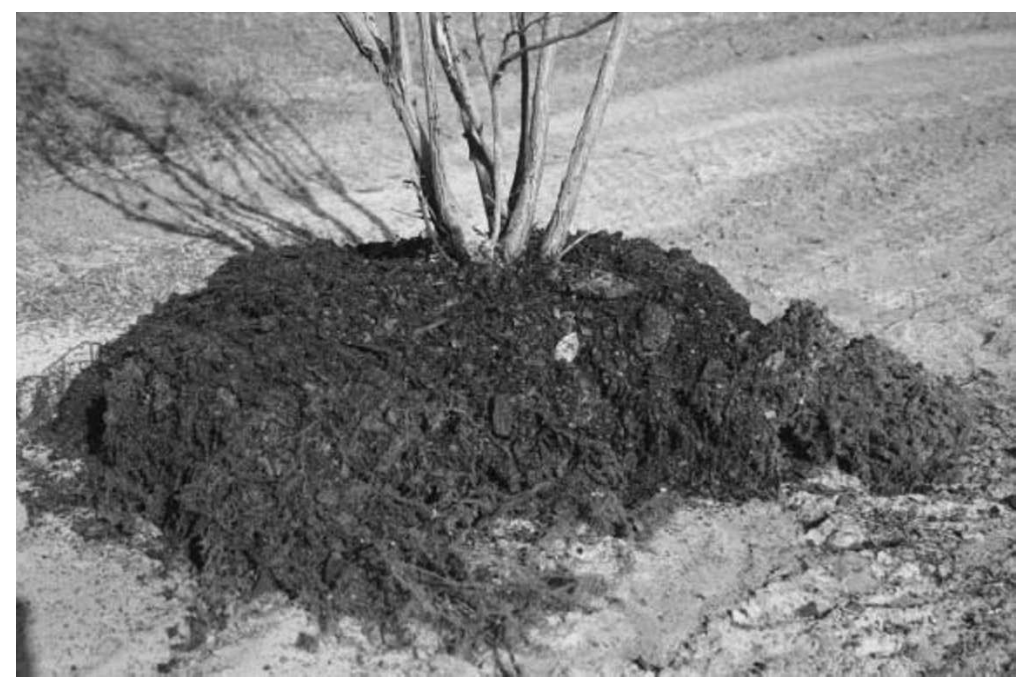

Fig. 4. An excavated blueberry plant removed from a pine bark bed. The root system is shallow and spreading and is primarily restricted to the pine bark layer.

ammonium adsorption to the bark can be eliminated as the primary cause of the high fertilizer demands observed in this study. Milled pine bark similar to that used in this study is reported to have about $40 \%$ to $45 \%$ (by volume) internal pore space and about $40 \%$ intraparticle pore space and is $\approx 20 \%$ solid matter (Krewer and Ruter, 2006). Water holding capacity of pine bark tends to increase as it ages but may range from $13 \%$ to $21 \%$ (by volume) (Krewer and Ruter, 2006). A 4-inch bed of pine bark with a $15 \%$ water-holding capacity will retain about 0.6 inches of water at field capacity. Frequent irrigation or rainfall would be required under Florida conditions if the root system is restricted to the pine bark layer. Moderate cation and low anion exchange capacities of pine bark combined with frequent applications of water can result in fertilizer loss through leaching, particularly when roots are restricted to the pine bark layer, as was observed in the present study. Repeated observations during the course of the study revealed that the soil under the pine bark layer was wet during most of the growing season. This may have limited oxygen diffusion and therefore root growth into the soil under the pine bark layer.
An alternative system is to incorporate pine bark into well-drained soils before planting. A homogenous amended soil profile could be established to a greater depth and allow for the possibility of deeper rooting and more efficient irrigation and fertilization management. White and Strik (2005) reported that saw dust used as a soil amendment and mulch reduced plant growth compared with no soil amendment. However, saw dust typically has a higher $\mathrm{C}: \mathrm{N}$ ratio than pine bark (1000:1 vs. 300:1) and a greater potential to render $\mathrm{N}$ temporarily unavailable for plant uptake (Krewer and Ruter, 2006). The pine bark system described in this study is inefficient in terms of water and fertilizer use and could have negative environmental consequences with regard to water use and nutrient leaching. More work is needed to evaluate different soil management systems for SHB with the goal of increasing water and fertilizer use efficiencies while maintaining good vigor and high fruit production.

\section{Literature cited}

Brannen, P., B. Cline, F. Hale, D. Horton, M. Czarnota, K. Jennings, W. Mitchem, D. Monks, D. Lockwood, G. Krewer, B. Bellinger, P. Guillebeau, and P. Summer. 2008. Southeast regional blueberry integrated management guide. 12 Aug. 2008. <http://www.smallfruits.org/Small FruitsRegGuide/Guides /2008/Blue berrySprayGuide21008.pdf $>$.

Clark, J.R. and J.N. Moore. 1991. Southern highbush blueberry response to mulch. HortTechnology 1:52-54.

Davidson, H. and R. Mecklenburg. 1981. Nursery management: Administration and culture. Prentice-Hall, Englewood Cliffs, NJ

Foster, W.J., R.D. Wright, M.M. Alley, and T.H. Yeager. 1983. Ammonium adsorption on a pine bark growing medium. J. Amer. Soc. Hort. Sci. 108: 548-551.

Heiberg, N. and R. Lunde. 2006. Effect of growth media on highbush blueberries grown in pots. Acta Hort. 715:219-223.

Krewer, G. and D.S. Nesmith. 2006. Blueberry fertilization in soil. 12 Aug. 2008. <http://www.smallfruits.org/Blueberries/ production/blueberryfert.pdf $>$.

Krewer, G. and J. Ruter. 2006. Fertilizing highbush blueberries in pine bark beds. 
12 Aug. 2008. <http://pubs.caes.uga. edu/caespubs/pubcd/B1291.htm>.

Lyrene, P. 1990. Low chill highbush blueberries. Fruit Var. J. 44:82-86.

Lyrene, P.M. and J.R. Ballington. 2006. Varieties and their characteristics. p. 2637. In: N.F. Childers and P.M. Lyrene (eds.). Blueberries: For growers, gardeners, promoters. Dr. Norman F. Childers Publications, Gainesville, FL.

Strik, B.C. and D. Yarborough. 2005. Blueberry production trends in North America, 1992 to 2003 , and predictions for growth. Hort Technology 15:391-398.

U.S. Department of Agriculture. 2007. Noncitrus fruits and nuts preliminary summary. 15 Aug. 2008. <http://usda. mannlib.cornell.edu/usda/current/ NoncFruiNu/NoncFruiNu-07-082008_revision.pdf>.

Whiddon, A. 2008. Commercial blueberry production methods in Hillsborough County. Proc. Florida State Hort. Soc. (In press).

White, L. and B. Strik. 2005. Fertility and soil management in newly established blueberry fields. Proc. Northwest Ctr. Small Fruits Res. 14:95-97.

Wilber, W.L. and J.G. Williamson. 2008. Effects of fertilizer rate on growth and fruiting of containerized southern highbush blueberry. HortScience 43:143-145.

Williamson, J.G. and P.M. Lyrene. 2004a. The Florida blueberry industry: A decade of growth. Proc. Florida State Hort. Soc. 117:234-235.

Williamson, J.G. and P.M. Lyrene. 2004b. Florida's commercial blueberry industry. 15 Aug. 2008. <http://edis. ifas.ufl.edu/AC031>.

Williamson, J.G. and P.M. Lyrene. 2004c. Blueberry varieties for Florida. 15 Aug. 2008. <http://edis.ifas.ufl.edu/HS215>.

Williamson, J.G., G. Krewer, G. Pavlis, and C.M. Mainland. 2006. Blueberry soil management, nutrition and irrigation. p. 60-74. In: N.F. Childers and P.M. Lyrene (eds.). Blueberries: For growers, gardeners, promoters. Dr. Norman F. Childers Publications, Gainesville, FL. 